\title{
OPEN Qualitative and quantitative methods detection of SDS based on polyelectrolyte microcapsules
}

\begin{abstract}
Aleksandr L. Kim, Egor V. Musin, Alexey V. Dubrovskii \& Sergey A. Tikhonenko
Sodium dodecyl sulfate (SDS) is the most widely used anionic surfactant. Its frequent use causes environmental pollution and negative effects on living organisms (even at low concentrations $\approx 20 \mu \mathrm{g} /$ $\mathrm{ml}$ ). Thus, cheap and fast methods are needed to detect this surfactant in wastewater and surface waters in order to prevent the negative effects of SDS on the environment and human beings. We discovered that sodium dodecyl sulfate is capable of destroying polyelectrolyte microcapsules, which has been demonstrated by the number of sedimented polyelectrolyte microcapsules (PMC) before and after incubation in SDS solution. Therefore, it was proposed to use PMCs to create qualitative and quantitative diagnostic systems for the determination of SDS in solution. The qualitative system is a polyelectrolyte microcapsules containing polyallylamine labeled with a fluorescent dye-FITC. An excess SDS concentration of more than $5 \mu \mathrm{g} / \mathrm{ml}$ in the analyzed medium leads to the destruction of PMC and an increase in the fluorescence intensity of the solution, which is recorded by a fluorometer. The quantitative diagnostic system is based on turbidimetry of the PMC suspension before and after incubation in an anionic surfactant solution. This system has a range of detectable SDS concentrations from 10 to $50 \mu \mathrm{g} / \mathrm{ml}$, with a standard deviation of no more than $11 \%$.
\end{abstract}

Surface active agents (surfactants) are a group of chemicals that have a polar hydrophilic headgroup and a nonpolar lipophilic hydrocarbon tail group ${ }^{1}$. This structure of surfactants allows them to be used in households and industries to increase the solubility of non-water-soluble substances, such as cleaning agents and emulsifiers. Global production of synthetic surfactants was 7.2 million tons in $2000^{2}$; since 2006, this value has risen to 12.5 million tons ${ }^{3}$ and these numbers will grow with the growth of the detergent and cosmetics industry. After use, the residual surfactants are discharged into the sewage system or directly into surface water, resulting in an increase in the level of surfactants in the environment and a significant impact on the ecosystem ${ }^{1}$.

The toxicity of surfactants to organisms is well known ${ }^{4}$ and depends on the physico-chemical properties of the surfactants themselves. They are generally classified into anionic, cationic, amphoteric and nonionic, depending on the charge of their headgroup. Among the groups listed above, the anionic surfactants are the most common in everyday and industrial uses and are toxic to both humans and the environment. In particular, anionic surfactants can bind to peptides, enzymes and DNA and alter their spatial layout (folding) and surface charge ${ }^{5}$. Such interactions can change the biological functions of biomolecules. Sodium dodecyl sulfate (SDS) is one of the most commonly used anionic surfactants, producing more than 3.8 million tons globally for industrial applications in cosmetics, clothing, food, fuel, and medicine ${ }^{6}$. Such mass production and use of SDS results in releases to the environment, with a semi-lethal concentration of not more than $45 \mu \mathrm{g} / \mathrm{ml}^{7}$ for algae, fish and crustaceans. In addition, it is known that surfactants can accumulate in the human body and cause autoimmune diseases, brain, liver, kidney and lung damage ${ }^{8,9}$. Besides the permissible limits for surfactants is $1 \mathrm{mg} / \mathrm{l}$ in water and at $0.5 \mathrm{mg} / \mathrm{l}$ for potable water ${ }^{10}$. In order to prevent negative environmental and human impacts of anionic surfactants (in particular SDS) in a timely manner, methods are needed to detect this surfactant in both wastewater and surface waters and in the soil ${ }^{11}$, food ${ }^{9}$, dust ${ }^{12,13}$, etc.

Spectrophotometric and potentiometric methods are the most common means of determining anionic surfactant, and chromatography is often used to concentrate and separate complex surfactant mixtures ${ }^{14}$. Most often, the ionometric determination of the surfactant is carried out using ionic electrodes, which makes it possible to determine the concentration of the substance under investigation in a short time (up to $30 \mathrm{~min}$ ). However, this method has low sensitivity $(280-600 \mu \mathrm{g} / \mathrm{ml})^{15}$ and low selectivity, which does not allow the determination of surfactants in relatively complex samples. Spectrophotometric methods are also labour-free (10-30 min) and have a high sensitivity of $0.001 \mu \mathrm{g} / \mathrm{ml}^{16,17}$. The main disadvantage is the low specificity and dilution of the 
sample to the measuring limit of $0.01 \mu \mathrm{g} / \mathrm{ml}$, which complicates the measurement procedure. These defects are corrected by chromatography, which allows separating the studied mixture and increasing the concentration of the required substance, but this procedure requires a minimum of several hours ${ }^{15}$.

There is therefore a need to develop a fast, low-cost method for determining anionic surfactant with high selectivity (specificity) that allows measurements to be made at environmentally toxic concentrations (10-50 $\mu \mathrm{g} /$ $\mathrm{ml}$ ). Therefore, a quick semi-quantitative or qualitative determination of the substance by means of various rapid tests, such as paper tests, is sufficient for a number of practical tasks to determine the surfactants before applying a more precise and labour-intensive method systems, tracer powders, fabrics, polymer films, tablets ${ }^{18-21}$. In particular, Dmitrienko's work with co-authors presents a method based on adsorption of a red-colored polyurethane foam (PUF) complex of an anionic surfactant with cation 1,10-fenantrolinate iron complex(II) ${ }^{22}$. This method allows the determination of anionic surfactants between 1 and $30 \mu \mathrm{g} / \mathrm{ml}$. But all these systems have a common disadvantage-the need to use toxic reagents.

Thus, we propose a non-toxic diagnostic system based on polyelectrolyte microcapsules for quick, cheap and highly selective qualitative and semi-quantitative determination of SDS in the medium.

\section{Materials and methods}

Polystyrene sulfonate sodium (PSS) and polyallylamine hydrochloride (PAH) with a molecular mass of $70 \mathrm{kDa}$ Sigma (Merck KGaA, Darmstadt, Germany), fluorescein isothiocyanate (FITC) Sigma (Merck KGaA, Darmstadt, Germany); ethylenediaminetetraacetic acid (EDTA), calcium chloride $\left(\mathrm{CaCl}_{2} \times 2 \mathrm{H}_{2} \mathrm{O}\right)$, sodium dodecyl sulfate, sodium chloride and sodium carbonate from Reahim (Reahim AO, St. Petersburg, Russian Federation) were used.

Preparation of fluorescently labelled PAH. FITC was slowly added to a stirring (300-400 rpm) solution of polyelectrolyte $(10 \mathrm{mg} / \mathrm{ml})$ in $50 \mathrm{mM}$ borate buffer, $\mathrm{pH} 9.0$. The components were fused in a molar ratio of FITC: $\mathrm{PAH}=1$ : 100. After that, its solution was incubated for 1.5-2 h. After incubation, the solution was dialyzed against water (10 l) overnight.

Preparation of $\mathrm{CaCO} 3$ microspherolites. $\quad 0.33 \mathrm{M} \mathrm{Na}_{2} \mathrm{CO}_{3}$ solution was rapidly added to the $0.33 \mathrm{M}$ $\mathrm{CaCl}_{2}$ stirring solution ${ }^{23}$. The stirring was continued for $30 \mathrm{~s}$. The suspension was maintained until complete precipitation of the formed particles. The process of "ripening" of microspherolites was controlled with the help of a light microscope. Then, the supernatant was decanted, the precipitate was washed with water and used to prepare PMC. The microparticles were obtained with an average diameter of $3 \pm 1 \mu \mathrm{m}$. The size of particles was controlled by light microscopy and determined in the program ImageJ.

Preparation of polyelectrolyte microcapsules. The polyelectrolyte microcapsules was obtained by alternately adsorbing the oppositely charged polyelectrolytes onto a dispersed microparticle (core), followed by dissolution of this cores. At the moment of dissolution of $\mathrm{CaCO}_{3}$ core the inner space of PMC is filled by interpolyelectrolyte complex 40. The microcapsule production process is shown in Fig. 1. Alternate adsorption of PSS and PAH on the surface of $\mathrm{CaCO}_{3}$ microspherolites was carried out in solutions of polyelectrolytes with a concentration of $2 \mathrm{mg} / \mathrm{ml}$ containing $0.5 \mathrm{M} \mathrm{NaCl}$. Each step of adsorption was followed by a triple wash with a $0.5 \mathrm{M} \mathrm{NaCl}$ solution, which was necessary to remove unabsorbed polymer molecules. The particles were separated from the supernatant by centrifugation. After applying the required number of layers, the carbonate kernels were dissolved in a $0.2 \mathrm{M}$ EDTA solution for $12 \mathrm{~h}$. The resulting capsules were washed three times with water to remove core decay products. In the case of a qualitative method for SDS determination PMC contained FITC labelled PAH. The microcapsules were obtained with an average diameter of $3 \pm 1 \mu \mathrm{m}$. The size of microcapsules was controlled by light microscopy and determined in the program ImageJ. The amount of the formed microcapsules was determined in the Goryaev chamber $(40 \times 106)$.

Registration of an envelope dissociation of FITC-labelled PAH from polyelectrolyte capsules. A microcapsules envelope dissociation was analysed by fluorescent spectroscopy. The polyelectrolyte microcapsules containing FITC-labelled PAH in their envelopes and encapsulating FITC-labelled were centrifuged at $3000 \mathrm{rpm}$ for one minute. Fluorescence of the supernatant was measured. The fluorescence spectra were registered with Cary Eclipse (USA) in a thermal controlled cuvette with $1 \mathrm{~cm}$ path length at light excitation with $273 \mathrm{~nm}$ wavelength. Each sample was measured three times.

Registration of optical density of polyelectrolyte microcapsules. The suspension of PMC $\left(4.1 \times 10^{8}\right.$ microcapsules) was added to a thermostated cuvette with an optical path length of $1 \mathrm{~cm}$ and measured spectrophotometrically at a wavelength of $450 \mathrm{~nm}$. Each sample was measured three times.

PMC incubation in SDS solution. Polyelectrolyte microcapsules were incubated in a solution of SDS of the required concentration with constant shaking on the vortex (500 rpm for the required time).

\section{Results and discussion}

Development of a qualitative method for SDS determination. We have found that polyelectrolyte microcapsules (PMC) of the (PAH/PSS) 3 PAH composition are destroyed in SDS solution. On Fig. 2 presents photographs of a precipitated suspension of PMC (120 million capsules, $3 \pm 1 \mu \mathrm{m})$ that incubated $20 \mathrm{~min}$ in distilled water and in a solution SDS $30 \mu \mathrm{g} / \mathrm{ml}$. The figure shows that the amount of deposited after incubation of PMC in solution SDS (B) is significantly lower than after the incubation of PMC in distilled water (A). 


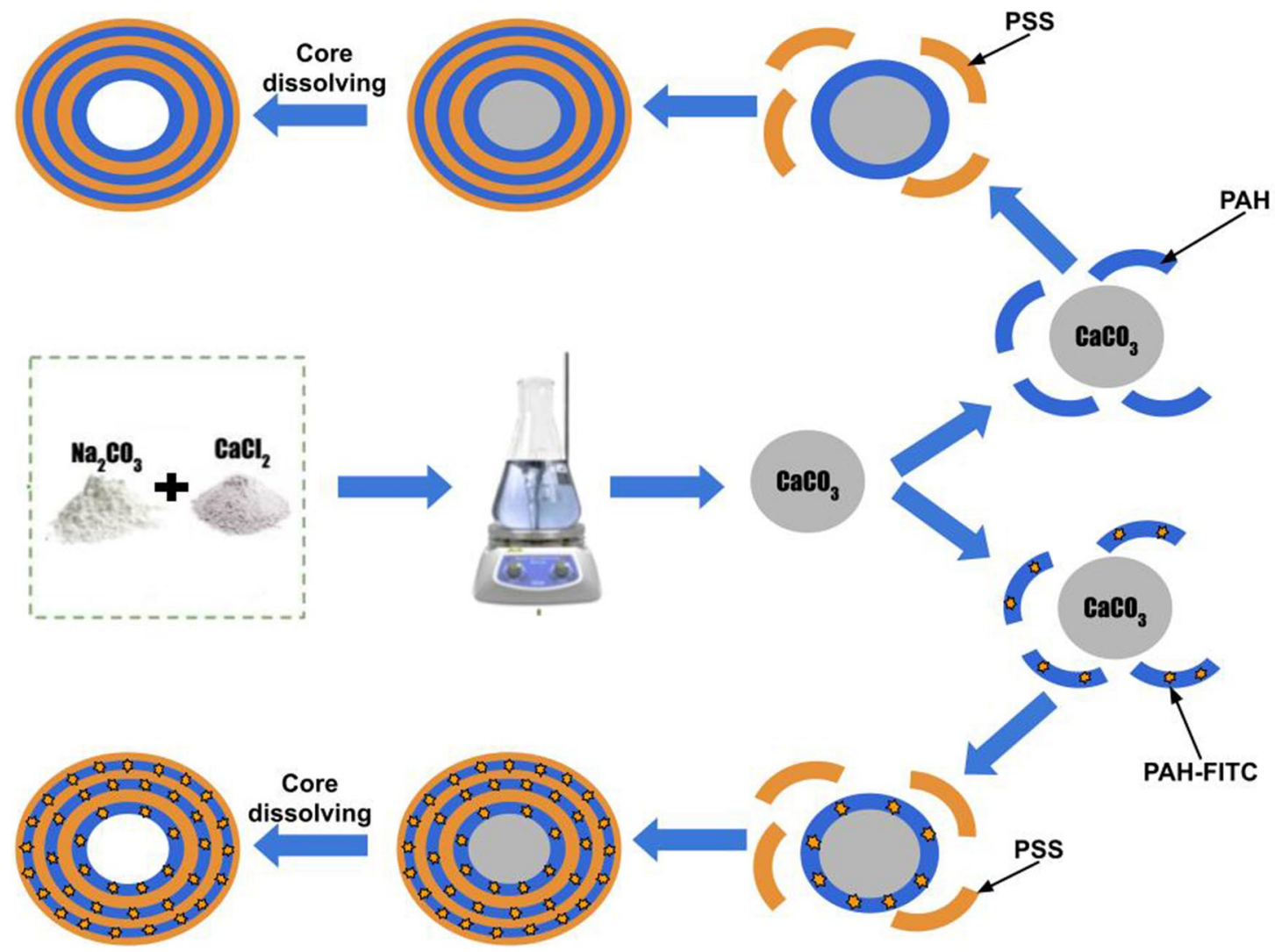

Figure 1. Stages of polyelectrolyte microcapsules preparation.

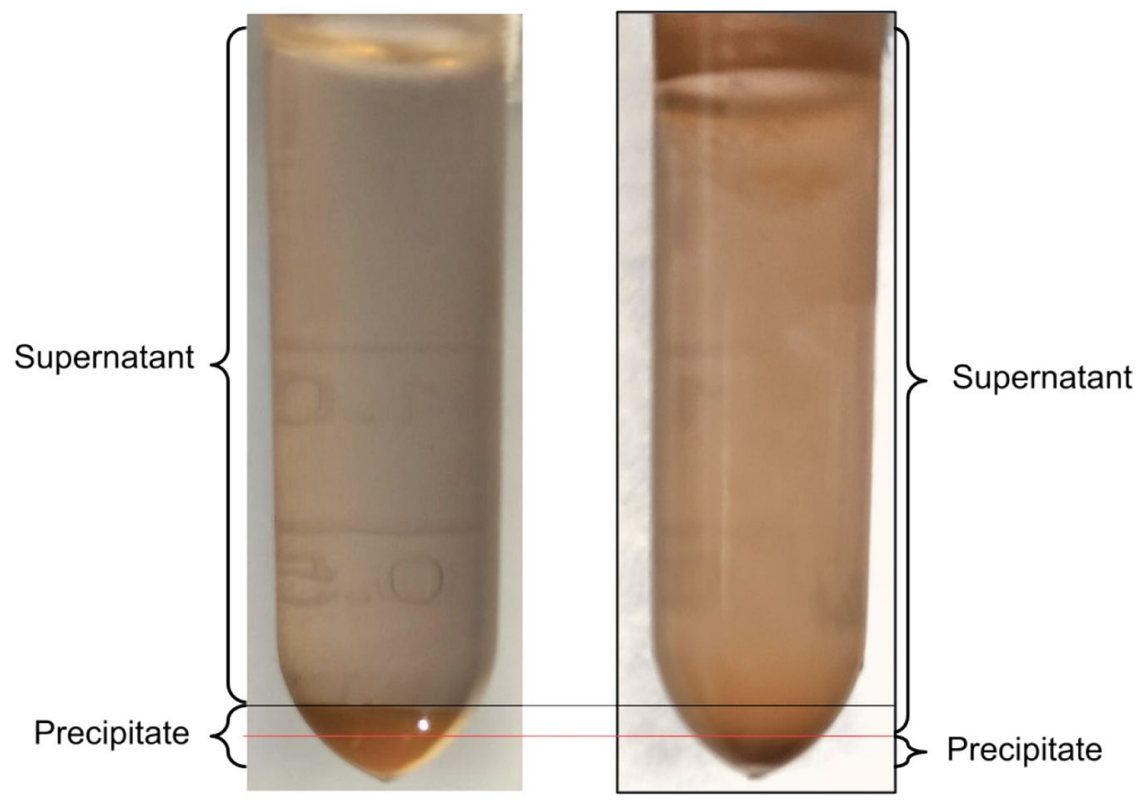

A

B

Figure 2. PMC precipitated suspensions incubated $20 \mathrm{~min}$ in distilled water (A) and in SDS solution $30 \mu \mathrm{g} / \mathrm{ml}$ (B). 


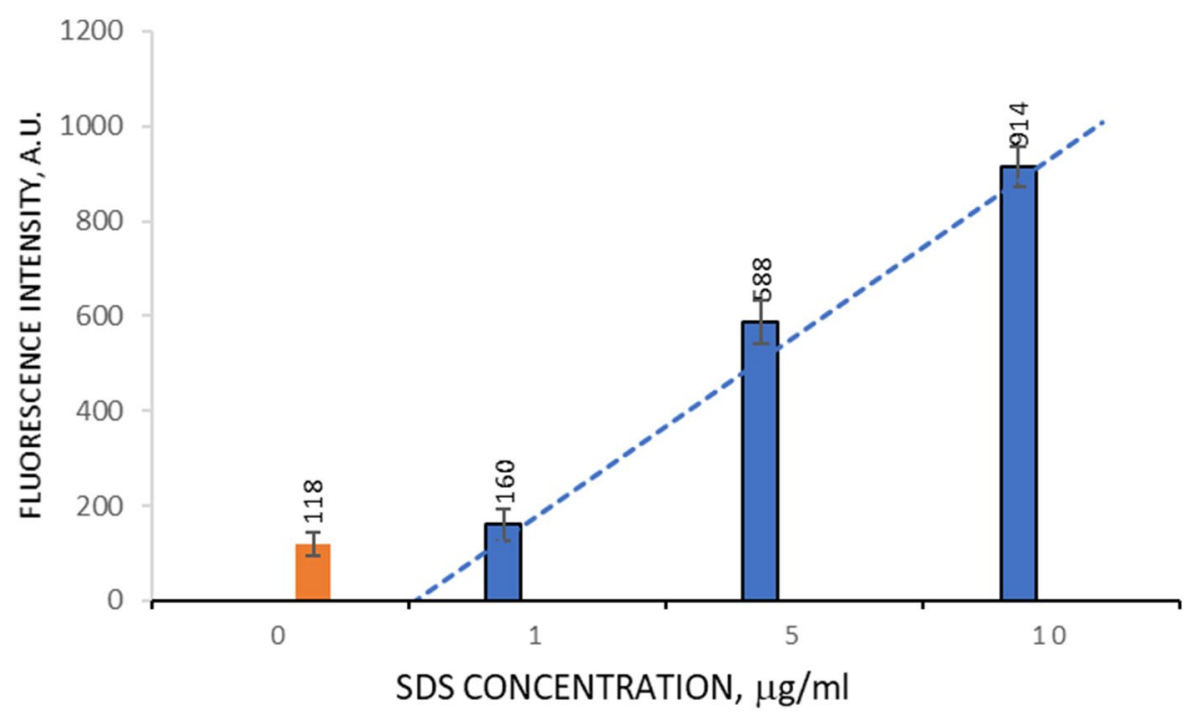

Figure 3. Fluorescence intensity of supernatant depending on SDS concentration $(\mu \mathrm{g} / \mathrm{ml})$.

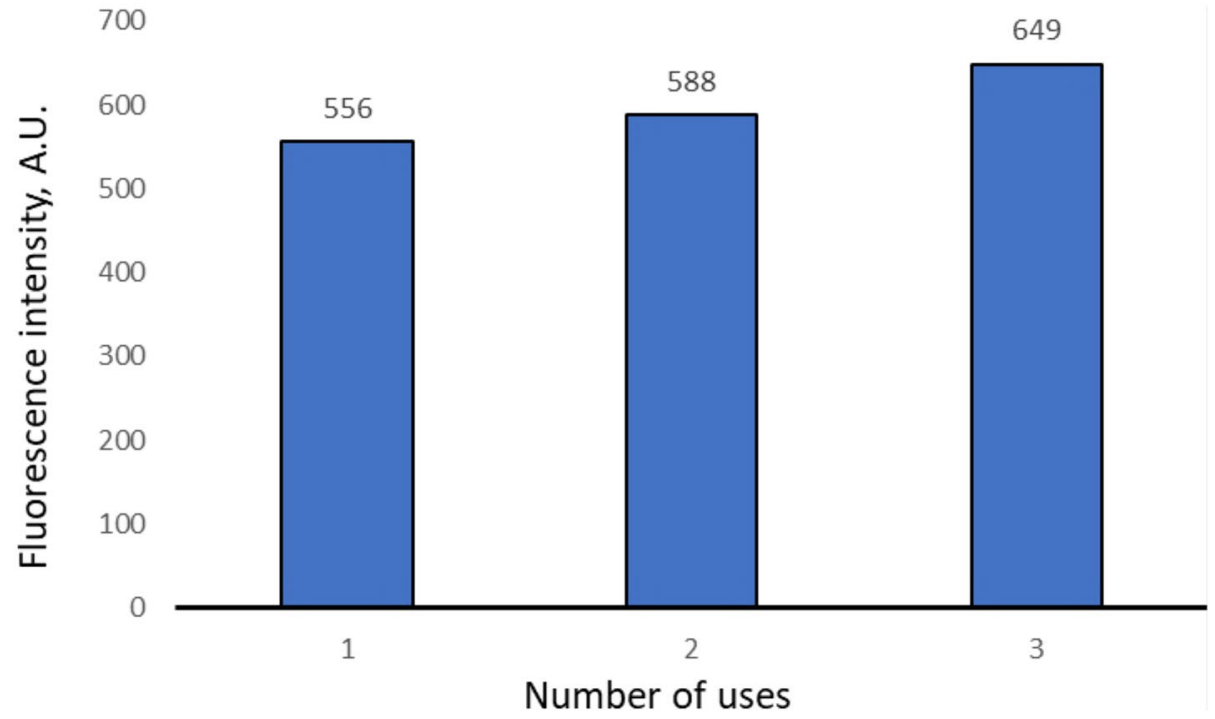

Figure 4. Fluorescence intensity of supernatant depending on the number of applications.

Based on this effect, we have proposed the use of PMC as a quality chemical method for determining SDS in water.

A seven-layer PMC containing PAH covalently linked to FITC (PAH-FITC) in all even layers was prepared. The destruction of PMC $\left(5 \times 10^{8}\right.$ microcapsules $)$ containing PAH-FITC will result in the release of the tagged polyelectrolyte into the supernatant if SDS is present in solution. Fluorescence of labeled polyelectrolyte in supernatant will signal the presence of anionic surfactant in solution. The resulting microcapsules were incubated in SDS solutions with concentrations of 1,5 and $10 \mu \mathrm{g} / \mathrm{ml}$ for $20 \mathrm{~min}$. After depositing the microcapsules at 15,000 revolutions over $1 \mathrm{~min}$, the fluorescence intensity of the supernatant was measured (Fig. 3 ).

From the figure it can be seen that significant differences in fluorescence intensity can be observed starting from a concentration of SDS of $5 \mu \mathrm{g} / \mathrm{ml}$. It can therefore be concluded that the system detects the presence of SDS in water at concentrations of $5 \mu \mathrm{g} / \mathrm{ml}$ and above.

One possible advantage of a PMC-based diagnostic system is their reuse. Therefore, we have studied the reuse of PMC-(PAH-FITC/PSS) ${ }_{3}$ PAH-FITC. For this purpose, 20 min were incubated PMC in a sample that contained SDS $5 \mu \mathrm{g} / \mathrm{ml}$. After incubation of the suspension, the capsules were precipitated and removed from sample. The capsules were transported to the next sample containing a SDS solution of the same concentration. The intensity of fluorescence of supernatants of each sample was measured. The procedure was carried out three times and the results are presented in Fig. 4.

As shown in Fig. 4, the threefold use of the same PMC has little effect on fluorescence intensity, the standard deviation of fluorescence intensity of the supernatant does not exceed $8 \%$. 


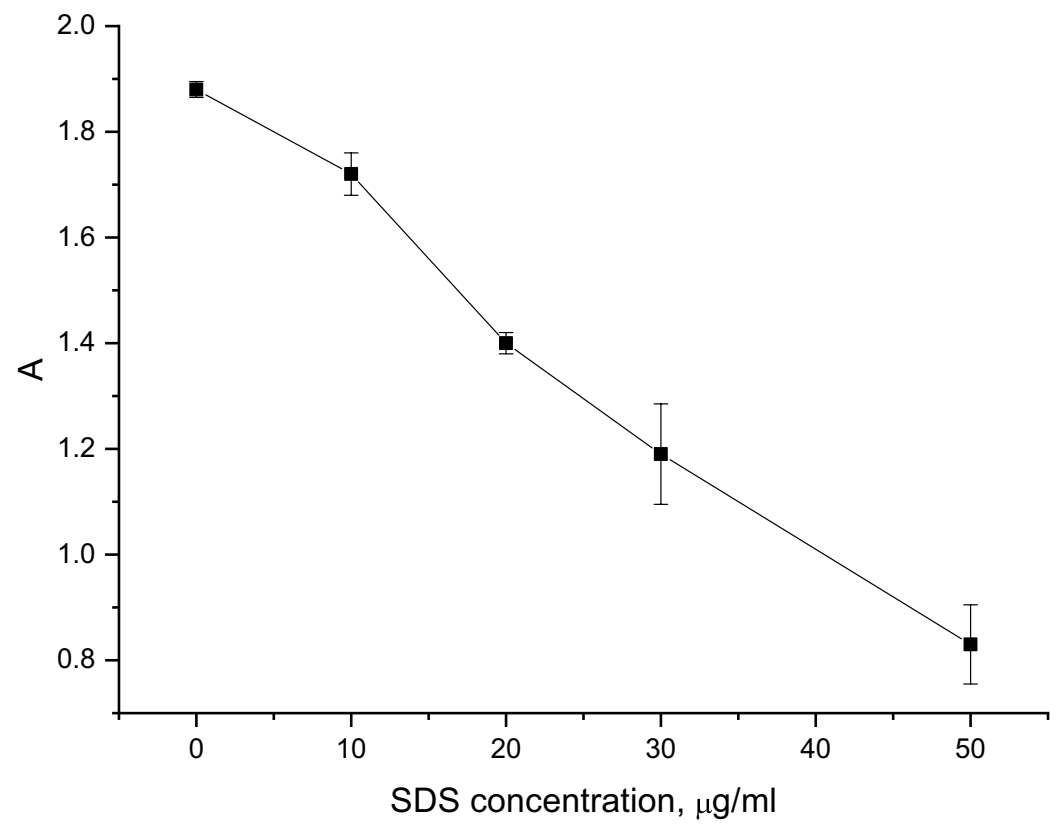

Figure 5. Light absorption of PMC $\left(2 \times 10^{8}\right.$ microcapsules per $\left.\mathrm{ml}\right)$ suspension by SDS concentration $(\mu \mathrm{g} / \mathrm{ml})$.

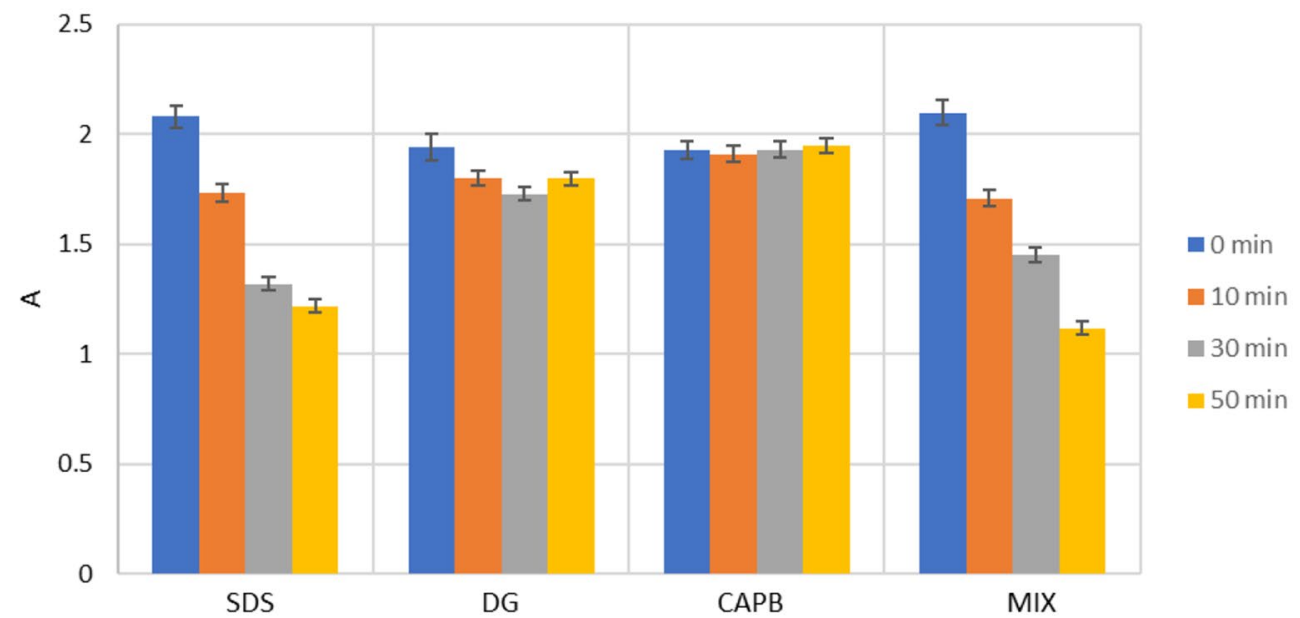

Figure 6. Light absorption of PMC suspension over time in the presence of various surfactants.

According to the results obtained above, we propose to use the resulting system for repeatedly qualitative determination of SDS in solution with a concentration above $5 \mu \mathrm{g} / \mathrm{ml}$, which corresponds to the fluorescence intensity of solution greater than 500 A.U.

Development of a quantitative method for SDS determination. In order to detect higher SDS concentrations, we have proposed another system for recording the break-up of microcapsules. We tracked the decay of the capsules by the turbidity of their suspension before and after incubation in SDS solutions of various concentrations. The results of this study are presented in Fig. 5.

It can be seen from the figure that the turbidity of the solution declines linearly with the surfactant concentration rising from 10 to $50 \mu \mathrm{g} / \mathrm{ml}$, with the standard deviation not exceeding $11 \%$. This means that SDS can be determined in a given concentration range.

The next step in our research was to establish the specificity of our detection systems. For this, we studied the change of the optical density of a suspension of microcapsules over time in the presence of various surfactants: amphoteric surfactant-cocamidopropyl betaine (CAPB, $30 \mu \mathrm{g} / \mathrm{ml}$ ); non-ionic surfactant—decyl glucoside (DG, $\mu \mathrm{g} / \mathrm{ml}$ ); anionic surfactant_sodium dodecyl sulfonate (SDS, $\mu \mathrm{g} / \mathrm{ml}$ ); a mixture of KAPB, DG and SDS (30 $\mu \mathrm{g} /$ $\mathrm{ml}$ each). The research results are shown in Fig. 6. 
It can be seen from the Fig. 6 that the CAPB and DG did not affect to microcapsules stability during 50 min of incubation. Also, the surfactants (DG and CAPB) after mixing with SDS did not affect to destruction of PMC by SDS solution. From these data, it can be concluded that the detection systems we have proposed are specific to SDS and will not falsely trigger in the presence of other surfactants in the solution.

\section{Conclusion}

It was discovered that polyelectrolyte microcapsules (PMC) of the composition (PAH/PSS)3PAH are destroyed in solution sodium dodecyl sulfate (SDS). And it was suggested that PMC be used as a quality chemical method to determine SDS in water. The resulting system detects the presence of SDS in water at concentrations of $5 \mu \mathrm{g} /$ $\mathrm{ml}$ and above, with the possibility of repeated application at a standard deviation of not more than $8 \%$.

In order to detect higher SDS concentrations, we have proposed a diagnostic system based on a change in the turbidity of the suspension before and after incubation in the solution of the anionic surfactant caused by the destruction of the PMC. The quantitative diagnostic system has a range of identifiable concentrations of SDS from 10 to $50 \mu \mathrm{g} / \mathrm{ml}$, with a standard deviation of no more than $11 \%$.

Received: 3 August 2021; Accepted: 21 December 2021

Published online: 07 January 2022

\section{References}

1. Ying, G.-G. Fate, behavior and effects of surfactants and their degradation products in the environment. Environ. Int. 32, 417-431. https://doi.org/10.1016/j.envint.2005.07.004 (2006).

2. Di Corcia, A. Characterization of surfactants and their biointermediates by liquid chromatography-mass spectrometry. J. Chromatogr. A 794, 165-185. https://doi.org/10.1016/S0021-9673(97)00678-X (1998).

3. Edser, C. Latest market analysis. Focus Surfactants 2006, 1-2. https://doi.org/10.1016/S1351-4210(06)71142-8 (2006).

4. Ivanković, T. \& Hrenović, J. Surfactants in the environment. Arch. Ind. Hyg. Toxicol. 61, 95-110. https://doi.org/10.2478/100041254-61-2010-1943 (2010).

5. Cserháti, T., Forgács, E. \& Oros, G. Biological activity and environmental impact of anionic surfactants. Environ. Int. 28, 337-348. https://doi.org/10.1016/S0160-4120(02)00032-6 (2002).

6. JSC Kuchuksulphate, S.A.U. SULQUISA, Alkim Alkali Kimya A.Ș., Lenzing AG, Xinli Chemical, Hunan Xiangheng Salt Chemical Co. Ltd., MINERA DE SANTA MARTA S.A., Saskatchewan Mining and Minerals Inc., Cordenka GmbH \& Co. KG, GRUPO INDUSTRIAL CRIMIDESA S.L., Elementis plc, Sichuan Hongya Qingyijiang Sodium Sulphate Co. Ltd., JIANGSU YINZHU CHEMICAL GROUP CO. LTD., Nafine Chemical Industry Group Co. Ltd., China Lumena New Materials Corporation. Sodium Sulphate Market Research Report: By Application-Global Market Size, Share, Trends Analysis and Growth Forecast to 2024 (Prescient \& Strategic Intelligence Private Limited, 2020). https://www.researchandmarkets.com/reports/5010710/sodium-sulphate-marketresearch-report-by.

7. Liwarska-Bizukojc, E., Miksch, K., Malachowska-Jutsz, A. \& Kalka, J. Acute toxicity and genotoxicity of five selected anionic and nonionic surfactants. Chemosphere 58, 1249-1253. https://doi.org/10.1016/j.chemosphere.2004.10.031 (2005).

8. Olkowska, E., Polkowska, Ż \& Namieśnik, J. Analytical procedures for the determination of surfactants in environmental samples. Talanta 88, 1-13. https://doi.org/10.1016/j.talanta.2011.10.034 (2012).

9. Sablayrolles, C., Montréjaud-Vignoles, M., Silvestre, J. \& Treilhou, M. Trace determination of linear alkylbenzene sulfonates: Application in artificially polluted soil-Carrots system. Int. J. Anal. Chem. 2009, 1-6. https://doi.org/10.1155/2009/404836 (2009).

10. Bhandari, P. S. \& Gogate, P. R. Adsorptive removal of sodium dodecyl sulfate using activated coconut shell based adsorbent: Kinetic and thermodynamic study. Desalin. Water Treat. 165, 111-123. https://doi.org/10.5004/dwt.2019.24491 (2019).

11. Nimer, M. et al. New sample treatment for determination of linear alkylbenzene sulfonate (LAS) in agricultural soils by liquid chromatography with fluorescence detection. Anal. Bioanal. Chem. 387, 2175-2184. https://doi.org/10.1007/s00216-006-1069-y (2007).

12. Vejrup, K. V. \& Wolkoff, P. Linear alkylbenzene sulfonates in indoor floor dust. Sci. Total Environ. 300, 51-58. https://doi.org/10. 1016/S0048-9697(02)00280-2 (2002).

13. Murakami, M. \& Takada, H. Perfluorinated surfactants (PFSs) in size-fractionated street dust in Tokyo. Chemosphere 73, 1172-1177. https://doi.org/10.1016/j.chemosphere.2008.07.063 (2008).

14. Базель, ЯР., Антал, ИП, Лавра, В. М. \& Кормош, ЖА. Методы определения анионных поверхностно-активных веществ. Журнал аналитической химии 69, 228-253. https://doi.org/10.7868/S0044450214010046 (2014).

15. Bazel, Y. R., Antal, I. P., Lavra, V. M. \& Kormosh, Z. A. Methods for the determination of anionic surfactants. J. Anal. Chem. 69, 211-236. https://doi.org/10.1134/S1061934814010043 (2014).

16. Dolenko, S. A., Alekseenko, E. Y. \& Kuschevskaya, N. F. Sorption-photometric determination of anionic surfactants in water. J. Anal. Chem. 65, 229-233. https://doi.org/10.1134/S1061934810030032 (2010).

17. He, Q. \& Chen, H. Flow injection spectrophotometric determination of anionic surfactants using methyl orange as chromogenic reagent. Fresenius. J. Anal. Chem. 367, 270-274. https://doi.org/10.1007/s002160000330 (2000).

18. Wyrwas, B. \& Zgoła-Grześkowiak, A. Continuous flow methylene blue active substances method for the determination of anionic surfactants in river water and biodegradation test samples. J. Surf. Deterg. 17, 191-198. https://doi.org/10.1007/s11743-013-1469-x (2014).

19. ASTM International. Standard Test Method for Foaming Properties of Surface-Active Agents (ASTM International, 2015).

20. Kurrey, R., Mahilang, M., Deb, M. K. \& Shrivas, K. Analytical approach on surface active agents in the environment and challenges. Trends Environ. Anal. Chem. 21, e00061. https://doi.org/10.1016/j.teac.2019.e00061 (2019).

21. Amelin, V. G. Artificial and natural fiber fabrics with immobilized di-and triaminotriarylmethane reagents in chemical test methods. J. Anal. Chem. 63, 297-299. https://doi.org/10.1134/S1061934808030192 (2008).

22. Дмитриенко С.Г., Пяткова Л.Н., Р.В.К. Оптические сорбционно-молекулярно-спектроскопические методы анализа. Сорбция ионных ассоциатов трис-\{\, 10-фенантролин) железа(Н) пенополиуретанами и ее аналитическое применение. Журн. аналит. Химии 51, 600-604 (1996).

23. Antipov, A. A. et al. Carbonate microparticles for hollow polyelectrolyte capsules fabrication. Colloids Surf. A Physicochem. Eng. Asp. 224, 175-183. https://doi.org/10.1016/S0927-7757(03)00195-X (2003).

\section{Author contributions}

Conceptualization, S.A.T. and E.V.M.; Data curation, A.V.D. and A.L.K.; Investigation, E.V.M., A.V.D. and A.L.K.; Methodology, A.V.D. and S.A.T.; Project administration, S.A.T.; Supervision, S.A.T.; Writing—original draft, 
A.L.K. and A.V.D; Writing-review and editing, A.L.K., A.V.D. and S.A.T. All authors have read and agreed to the published version of the manuscript.

\section{Funding}

This research was funded by State assignment of Russian Federation: 075-00381-21-00.

\section{Competing interests}

The authors declare no competing interests.

\section{Additional information}

Correspondence and requests for materials should be addressed to S.A.T.

Reprints and permissions information is available at www.nature.com/reprints.

Publisher's note Springer Nature remains neutral with regard to jurisdictional claims in published maps and institutional affiliations.

(c) (i) Open Access This article is licensed under a Creative Commons Attribution 4.0 International License, which permits use, sharing, adaptation, distribution and reproduction in any medium or format, as long as you give appropriate credit to the original author(s) and the source, provide a link to the Creative Commons licence, and indicate if changes were made. The images or other third party material in this article are included in the article's Creative Commons licence, unless indicated otherwise in a credit line to the material. If material is not included in the article's Creative Commons licence and your intended use is not permitted by statutory regulation or exceeds the permitted use, you will need to obtain permission directly from the copyright holder. To view a copy of this licence, visit http://creativecommons.org/licenses/by/4.0/.

(c) The Author(s) 2022 